\title{
Investigating how Business Process Ambidexterity facilitates business-IT alignment in public sector organizations.
}

\author{
Tomek Helbin \\ Department of Business Informatics and Operations Management, \\ Faculty of Economics and Business Administration, Ghent University \\ Ghent, Belgium \\ tomasz.helbin@ugent.be
}

\begin{abstract}
In today's world of digital transformation and global hyper-competition the need for organizations to manage and innovate their Business Processes in both incremental and disruptive ways is greater than ever, both for private and public organizations. The nascent concept of Business Process Ambidexterity (balancing process exploitation and exploration) has been receiving a growing interest in the academia, and my research aims to address three research gaps: (1) the conceptualization of Business Process Ambidexterity and guidance on its implementation; (2) its impact on business-IT alignment, and (3) the specific contingency factors of Business Process Ambidexterity in the public sector. I will address these gaps through a research plan, covering a large-scale survey, extreme case research, Delphi study and design science research. At this stage I have completed a Systematic Literature Review of Business Process Ambidexterity, and I am preparing the next steps of my research.
\end{abstract}

Keywords-Business Process Ambidexterity, IT Governance, Business-IT alignment, BPM, Organisational Ambidexterity

\section{INTRODUCTION}

\section{A. Business Process Management (BPM) and Process Orientation (PO)}

Business Process Management (BPM) is defined as all efforts to analyse and continually improve fundamental activities of organisation's operations (adapted from [1]). BPM was proven to positively impact organisations' performance and competitiveness [2], in particular for processes spanning different domains and departments [3]. Additionally, the academic community has recently issued calls to focus more research on BPM implementation, which is arguably lagging behind [4], and also to reach out beyond IT-driven process modelling towards a holistic view of the managerial aspects of process management [5].

Several attempts exist to categorize the main elements of BPM. For instance, researchers have proposed two key elements of process management: process control and incremental process improvement [6]. Six core elements, or success factors of BPM have been identified [7]: strategic alignment, governance, methods, information technology, people and culture. On the other hand, [8] proposed a framework capturing six main BPM capability areas and 17 sub-areas, based on organizational theories and a comprehensive sample of 69 business process maturity models. The capability areas are as follows:
- Process modelling: this initial stage in the business process lifecycle dedicated to design and analysis of business processes;

- Process deployment: comprises implementation, enactment, measurement and control;

- Process optimization: improvement of the business process;

- Process management: covers daily management, as well as aligning with business strategy and stakeholder relationships;

- Process-oriented culture: process-oriented values, attitudes and behaviors;

- Process-oriented structure: process-oriented organization chart and governance bodies.

\section{B. Business Process Ambidexterity (challenge 1)}

Today, we are facing the fourth industrial revolution driven by social, mobile, cloud and smart technologies [4]. In order to reap benefits from "new IT" (e.g. Artificial Intelligence, Internet of Things [IoT], blockchain) and their (often disruptive) opportunities for digital process innovation, [9] argues that organisations need to simultaneously pursue exploitative and explorative process capabilities in order to deliver both incremental and disruptive process innovation. This so-called Business Process Ambidexterity provides a fascinating challenge for the BPM discipline since it requires to move beyond its founding paradigm of process control and optimisation, towards identifying opportunities for process disruption and "the creation of process designs that truly excite customers" [10] (p. 636).

The concept of organizational ambidexterity was introduced by [11], who proposed setting up separate organizational structures to manage contradictory forces in an organization. The organizational tension between exploration and exploitation can be traced back to the seminal work of [12], who described the inherently contradictory dichotomy between exploration and exploitation in organizational learning. Exploration can be defined as searching and experimenting, while exploitation drives profit from the results when optimizing the operation [13]. Ambidexterity has eventually been defined as the dynamic capability of balancing these two opposing activities [14]. More recently, the need to balance contradictory activities has been replaced with the concept of paradox thinking, where the tensions are actually beneficial and enlightening [15]. Ample empirical evidence proves that ambidexterity is beneficial for both 
organisations' productivity and innovativeness, in particular in uncertain market conditions [16]. Moreover, organisations with greater technological capability are proven to benefit to an even greater extent from ambidexterity [17].

From an IT perspective, the concept of 'bimodal IT' (IT structures pursuing both explorative and exploitative objectives) has received the attention of researchers and practitioners pursuing ambidexterity [18]. However, it is still unsure whether this approach truly delivers sustainable ambidexterity [19].

One of the key limitations of analyzing Business Process Ambidexterity is the lack of a clear definition or a widely recognized conceptual framework for this term. We have identified two definitions of process ambidexterity in the literature: (1) the first one focusing on firms' capabilities in a structural ambidexterity setting: firm's capability for utilizing both process alignment and process adaptability [20]; and (2) the second one concentrating on the "dynamic equilibrium" in the setting of contextual ambidexterity: the dynamic equilibrium state of business process efficiency and business process flexibility" [21].

Guidance for practitioners in this field still remains fairly limited. Looking at the BP lifecycle, BP ambidexterity plays the most critical role in BP modelling, and optimization capabilities. Following this, a few researchers attempted to conceptualize new frameworks for the modelling phase of ambidextrous processes $[15,16]$ and the optimization phase [24]. The fundamental question of how Business Process Ambidexterity should be implemented remains nevertheless unanswered. Should organizations focus on structural Business Process Ambidexterity, and as such concentrate primarily on explorative processes? Or, alternatively should they design their processes to be both exploitative and explorative? How should they pursue both paths?

\section{Business Process Ambidexterity and Business-IT alignment (challenge 2)}

Business-IT alignment plays a critical role in management of information systems, being the corner stone of digital transformation and digitalisation [25]. As such, business-IT alignment, which is aimed at ensuring that key IT resources are aligned with an organisational strategy in order to improve the organisation's performance [26], has been one of the main concerns of IT practitioners and IS researchers for the past 30 years [27]. Studies have recently moved beyond the paradigm of aligning IT with strategies, towards the concept of IT actually being the strategy, which can be conceptualised as the Digital Strategy [28]. [29] demonstrated the surprising lack of convergence between IT alignment and BPM studies, and proposes to analyse IT alignment from the perspective of BPM. [30] argued that business value was created from IT using BPM, positioning BPM as a critical enabler of Business-IT alignment. [31] paraphrased Nicholas Carr by stating "IT does not matter, business processes do" [32]. Moreover, some researchers argued that digitalization can actually resolve the exploration/exploitation paradox, and they proposed three digitalization paths aimed at delivering ambidexterity. The paths were: assets digitalization, digitally based process integration, and disruptive analytics-led decision-making [33]. In this context the role of Enterprise Architecture is critical, as an enabler of business-IT alignment in an agile enterprise [34].
Is there then a relationship between Business Process Ambidexterity and business-IT alignment? Some researchers argued that business-IT alignment could lead to greater process innovation [35] and organizational ambidexterity [36]. [37] provided a framework for ambidexterity facilitating business-IT alignment and [38] proposed a method to evaluate processes, aiming to align business and IT. [39] speculated that emergent ambidextrous IT capabilities could indeed advance IT strategic alignment.

\section{Process management in the public sector (challenge 3)}

While BPM is applied in many organizations of different types, BPM studies mainly focus on large and private organizations. Nonetheless, public sector organizations also profit from improving their processes and from digital process innovation to better serve their customers/tax payers. As argued by [5] context awareness is one of the ten principles of good BPM, and [40] provide evidence that the maturity of processes is generally lower in the public sector, which does not face the competitive pressure of the private sector. Nevertheless, even in the public sector, there are pockets of digital innovation and organisational ambidexterity, as documented by [41] in the IoT smart city projects. Also, a few papers have explored organisational ambidexterity in the public sector - looking for specific enablers [42] or strategies [43].

Thus, this project proposal addresses the identified gaps by looking at digital process innovation and organisational ambidexterity in the public sector and the related IT alignment, especially in EU institutions and EU member state administrations. Being an employee at the European Commission in IT governance, the applicant benefits from first access to the targeted units of analysis.

\section{AIM OF THE RESEARCH}

The purpose of the research is to understand if and how public sector organisations implement Business Process Ambidexterity, and whether this facilitates IT alignment, which increases in importance in the digital era.

The research will provide valuable contribution to academia by addressing several gaps in the body of knowledge: the so far unexplored capabilities, environments and contingency factors of Business Process Ambidexterity; the relationship between Business Process Ambidexterity and IT alignment, in particular in the context of digital innovation; and finally, it will broaden the knowledge about BPM implementation in the public sector. The research will also respond to the call of [4] to focus on the implementational aspects of BPM.

One of the greatest challenges for practitioners in the digital era, in both the private and the public sector, is building appropriate BPM and IT structures enabling both incremental and disruptive innovation. The research will address this need by delivering a decision tool, supporting the practitioners in the creation of ambidextrous processes.

The research aims to answer the following questions:

RQ1. To which extent do public organizations develop capabilities for Business Process Ambidexterity, and how?

The output are patterns or evolution paths to evolve in Business Process Ambidexterity in a public sector context. 
RQ2. How can Business Process Ambidexterity facilitate IT alignment in the digital era, considering different environments and contingency factors within the public sector (such as domains, organisational structures and cultures, size)?

The output is a research model with correlations between capabilities for Business Process Ambidexterity and IT alignment capabilities, including contextual variables that affect those correlations.

RQ3. How can public organizations develop ambidextrous processes, to achieve better IT alignment?

The output will be practical guidelines in the sense of decision criteria in a decision tool (i.e. as an alternative to a prescriptive maturity model).

\section{Methodology}

The $\mathrm{PhD}$ student's work and experience in the private sector and the EU public service, and in particular his current role as IT Portfolio Manager, and member of the European Commission's IT governance team, will strongly facilitate the execution of the research. This will be facilitated through firsthand access to a wide array of project documentation and analysis, as well as direct contact with stakeholders across the European Commission, other EU Institutions and Agencies, and EU Member State administrations. This provides synergies and complements the objectives of the research, enriching it with a practitioner's perspective. There are nevertheless also privacy and ethical concerns, which will need to be thoroughly analysed in the preparation of the research.

\section{A. Methodology per research question}

Below is the proposed methodology for each question:

RQ1. To which extent do public organizations develop capabilities for Business Process Ambidexterity, and how?

We conduct a large-scale survey research within the EU Institutions based in Brussels and Luxembourg (in particular the European Commission, the European Parliament, and the Council of the EU), EU Agencies (in particular those working on IT themes: eu-LISA and ENISA), and a selection of EU Member State national administrations (chosen based on identified contingency factors), in order to get insight into the AS-IS situation, starting from the validated framework of the supervisor [8] and literature on organizational ambidexterity $[44,45,14,16]$. The survey data will be used for patternmatching purposes, to find best practices, and to select cases for RQ2.

RQ2. How can Business Process Ambidexterity facilitate IT alignment in the digital era, considering different environments and contingency factors within the public sector (such as domains, organisational structures and cultures, size)?

We apply an extreme case research approach [46] to get deeper explanations about the TO-BE situation. Based on RQ1, we select those EU case organizations that have advanced most in terms of Business Process Ambidexterity (top 10\%), and investigate their IT alignment strategies, hurdles and success stories. The findings are refined for context-awareness [5], by considering a variety of contextual variables that elicit from the data.
RQ3. How can public organizations build ambidextrous processes, to achieve better IT alignment?

We continue with the findings from RQ1 (AS-IS) and RQ2 (TO-BE) to formulate concrete guidelines in RQ3. A Delphi study $[47,48]$ is conducted for criteria ranking. Afterwards, we follow Design-Science Research [49] [50] to build and test a practical and methodologically sound decision tool, using two iterative build-test cycles.

\section{B. Timeline}

Below is the timeline of the activities. Each research question corresponds to a work package (WP) with different phases.

1) WP1 Survey (Year 1) => Evolution paths via patternmatching, and selection of best cases

- Output: paper for an Information Systems (IS) conference (e.g. BPM, ECIS, ICIS, HICCS); first A1 paper with a statistical state-of-play on EU level and pattern-matching exercise

\begin{tabular}{|l|l|l|}
\hline WP1.1 & $\begin{array}{l}\text { Systematic Literature Review of Business } \\
\text { Process Ambidexterity }\end{array}$ & $\begin{array}{l}\text { Q1-Q2 } \\
\text { Year1 }\end{array}$ \\
\hline WP1.2 & $\begin{array}{l}\text { A priori specifying the theoretical constructs } \\
\text { (with a pre-test with PhD students and EU } \\
\text { servants for questions' clarity) }\end{array}$ & Q3 Year1 \\
\hline WP1.3 & Large-scale data collection & Q3 Year1 \\
\hline WP1.4 & Data analysis with pattern-matching & $\begin{array}{l}\text { Q3-Q4 } \\
\text { Year1 }\end{array}$ \\
\hline WP1.5 & Case selection for RQ2 & Q4 Year1 \\
\hline WP1.6 & Consolidating the finding / Writing up & Q4 Year1 \\
\hline
\end{tabular}

2) WP2 Extreme case research (Year 2) $=>$ Contextual factors to be considered when aligning IT with PM ambidexterity

- Output: paper for an IS conference (e.g. BPM, ECIS, ICIS, HICCS); second A1 paper with a theoretical contingency model to link Business Process Ambidexterity with business-IT alignment

\begin{tabular}{|l|l|l|}
\hline WP2.1 & Establishing a case study protocol & Q1 Year2 \\
\hline WP2.2 & $\begin{array}{l}\text { Primary data collection with data triangulation, } \\
\text { and iterative coding }\end{array}$ & $\begin{array}{l}\text { Q2-Q3 } \\
\text { Year2 }\end{array}$ \\
\hline WP2.3 & Within-case and cross-case analysis & $\begin{array}{l}\text { Q3-Q4 } \\
\text { Year2 }\end{array}$ \\
\hline WP2.4 & Consolidating the finding / Writing up & Q4 Year2 \\
\hline
\end{tabular}

3) WP3 Delphi study (Year 3) => Decision criteria for aligning IT with PM ambidexterity

- Output: paper for an IS conference (e.g. BPM, ECIS, ICIS, HICCS); third A1 paper reporting on the decision criteria elicitation and ranking

\begin{tabular}{|l|l|c|}
\hline WP3.1 & Delphi protocol & Q1 Year3 \\
\hline WP3.2 & Phase 1: brainstorming & Q1 Year3 \\
\hline WP3.3 & $\begin{array}{l}\text { Phase 2: narrowing down by consensus- } \\
\text { seeking decision-making }\end{array}$ & Q2 Year3 \\
\hline WP3.4 & $\begin{array}{l}\text { Phase 3: ranking and weighing criteria by } \\
\text { multi-criteria decision-making }\end{array}$ & Q2 Year3 \\
\hline
\end{tabular}




\section{B. Preparation of large-scale survey}

4) WP4 Design-Science Research (Year 3-4) => Context-aware decision tool for aligning IT with Business Process Ambidexterity

- Output: paper for an IS conference (e.g. BPM, ECIS, ICIS, HICCS); third A1 paper reporting on the build and evaluate phases of the decision tool

\begin{tabular}{|l|l|l|}
\hline WP4.1 & $\begin{array}{l}\text { Build tool sub artefacts (constructs, model, tool } \\
\text { method, instantiation) }\end{array}$ & Q4 Year3 \\
\hline WP4.2 & $\begin{array}{l}\text { Pilot test (= design evaluation for utility, } \\
\text { quality, efficacy) by means of testers (5 EU } \\
\text { servants working with process managers and IT } \\
\text { managers) }\end{array}$ & Year4 \\
\hline WP4.3 & Re-build phase considering early feedback & Q1 Year4 \\
\hline WP4.4 & $\begin{array}{l}\text { Test phase by means of case studies (5 EU } \\
\text { administrations wishing to advance in PM } \\
\text { ambidexterity) }\end{array}$ & Q2 Year4 \\
\hline WP4.5 & Consolidating the finding / Writing up & Q3 Year4 \\
\hline
\end{tabular}

\section{CURRENT STATUS AND NEXT STEPS}

In reference to the plan above, I am currently in WP1 (as of March 2019). I have just completed the Systematic Literature Review (WP1.1), and I am in the process of starting preparations of the large-scale survey (WP1.2).

\section{A. Systematic Literature Review (SLR)}

Our SLR was following an SLR Protocol [51], and the search strategy was based on three steps: (1) search in predefined databases using wildcard keywords, which generated 892 articles; (2) qualitative screening of articles based on exclusion criteria, which narrowed down our search to 47 articles; and finally (3) analysis of the complete text of the articles and answering to SLR research questions. The research questions aimed to position the articles in the context of established frameworks for BP capability areas [8], types of ambidexterity (structural and contextual [45]), IT governance elements [26] and finally their relationship with Business-IT alignment.

In our research, we have divided all articles into two main strands of research focusing on: (1) organizational capabilities enabling Business Process Ambidexterity, and (2) the actual dynamic balance between exploration and exploitation in BPM, which is enabled by the modelling and optimization stages of the business process lifecycle. As there was no widely accepted definition of Business Process Ambidexterity, we proposed one for future use, based on the concept of paradoxical thinking. We have not identified any evidence that Business Process Ambidexterity enables Business-IT alignment in an ambidextrous setting; however, we highlighted that several studies show a mutually reinforcing relationship between Business Process Ambidexterity and digitalization. The main research gap we highlighted was the lack of a conceptual model of. Business Process Ambidexterity, and the fragmented guidelines on Business Process Ambidexterity implementation. The full SLR is available in the proceedings of this conference.

We are currently reviewing the identified frameworks for Business Process Ambidexterity ([14], [22], [52], [53], [54]) to prepare the survey, and looking to expand the potential scope of the survey with frameworks from past research in Business Process Reengineering and New Public Management. Based on the analysis in the SLR none of the identified frameworks provide a holistic conceptualization of Business Process Ambidexterity.

Acknowledgements. This $\mathrm{PhD}$ project will be organized by Ghent University (Belgium) under the supervision of Prof. dr. Amy Van Looy.

\section{REFERENCES}

[3] M. von Rosing, U. Foldager, M. Hove, J. von Scheel, and A. F. Bøgebjerg, "Working with the Business Process Management (BPM) Life Cycle," 2015, pp. 269-345.

[4] W. M. P. Van Der Aalst, M. La Rosa, and F. M. Santoro, "Business process management: Don't forget to improve the process!," Bus. Inf. Syst. Eng., vol. 58, no. 1, pp. 1-6, 2016.

[5] J. vom Brocke, J. Recker, P. Trkman, W. Mertens, and S. Viaene, "Ten Principles of Good Business Process Management.," Bus. Process Manag. J., 2014.

[6] A. C. L. Yeung, T. C. E. Cheng, and L.-Y. Chan, "From Customer Orientation to Customer Satisfaction: The Gap Between Theory and Practice," IEEE Trans. Eng. Manag., vol. 51, no. 1, pp. 85-97, Feb. 2004.

[7] M. Rosemann and J. vom Brocke, "The six core elements of business process management," in Handbook on Business Process Management 1: Introduction, Methods, and Information Systems, 2015, pp. 105-122.

[8] A. Van Looy, M. De Backer, and G. Poels, "A conceptual framework and classification of capability areas for business process maturity," Enterp. Inf. Syst., vol. 8, no. 2, pp. 188-224, 2014

[9] M. Rosemann, "Proposals for future BPM research directions," Lect. Notes Bus. Inf. Process., vol. 181 LNBIP, pp. 1-15, 2014

[10] T. Kohlborn, O. Mueller, J. Poeppelbuss, and M. Roeglinger, "Interview with Michael Rosemann on ambidextrous business process management," Bus. Process Manag. J., vol. 20, no. 4, pp. 634-638, 2014

[11] R. B. Duncan, "The ambidextrous organization: Designing dual structures for innovation. R. H. Kilmann, L. R. Pondy, D. Slevin, eds.," Manag. Organ., vol. 1, pp. 167-188, 1976.

[12] J. G. March, "Exploration and Exploitation in Organizational Learning," Organ. Sci., vol. 2, no. 1, pp. 71-87, 1991.

[13] D. Lavie, U. Stettner, and M. L. Tushman, "Exploration and Exploitation Within and Across Organizations," Acad. Manag. Ann., vol. 4, no. 1, pp. 1941-6067, 2010.

[14] Z.-L. He and P.-K. Wong, "Exploration vs. Exploitation: An Empirical Test of the Ambidexterity Hypothesis," Organ. Sci., vol. 15 , no. 4, pp. 481-494, 2004.

[15] A. Martini, B. T. Laugen, L. Gastaldi, and M. Corso, "Continuous innovation: towards a paradoxical, ambidextrous combination of exploration and exploitation," Int. J. Technol. Manag., vol. 61, no. 1, p. 1, 2013.

[16] C. A. O'Reilly and M. L. Tushman, "Organizational 
Ambidexterity: Past, Present and Future Academy of Management Perspectives," Acad. Manag. Perspect., vol. 27, no. 4, pp. 324-338, 2013

M. C. Goossen, N. Bazzazian, and C. Phelps, "Consistently Capricious: The Performance Effects of Simultaneous and Sequential Ambidexterity," Acad. Manag. Proc., vol. 2012, no. 1, p. 16311, Jul. 2012

[18] B. Horlach, P. Drews, I. Schirmer, and T. Boehmann, "Increasing the Agility of IT Delivery: Five Types of Bimodal IT Organization," in Proceedings of the 50th Hawaii International Conference on System Sciences, 2017.

[19] I. Haffke, B. Kalgovas, and A. Benlian, "The Transformative Role of Bimodal IT in an Era of Digital Business," 2017.

[20] S. D. Bot and P. E. Renaud, "Process Ambidexterity for IT Entrepreneurship,” Technol. Innov. Manag. Rev., vol. 2, no. 8 , pp. 16-22, 2012.

[21] R. Xie, H. Ling, C. Zhang, X. Rong, L. Hong, and Z. Cheng, "Effect of business process management on firm performance: An ambidexterity perspective," Bus. Manag. Electron. Inf. (BMEI), 2011 Int. Conf., vol. 3, pp. 341-345, 2011.

[22] S. C. H. Ng, J. M. Rungtusanatham, X. Zhao, and T. S. Lee, "Examining process management via the lens of exploitation and exploration: Reconceptualization and scale development," Int. J. Prod. Econ., vol. 163, pp. 1-15, 2015

[23] H. Santos and C. Alves, "Exploring the Ambidextrous Analysis of Business Processes : A Design Science," in ICEIS 2017, Springer International Publishing, 2018, pp. 543-566.

[24] P. Afflerbach and L. Frank, "Customer Experience Versus Process Efficiency: Towards an Analytical Framework About Ambidextrous BPM," in 37th International Conference on Information Systems (ICIS), 2016, vol. 4801, pp. 1-21.

[25] C. Kahre, D. Hoffmann, and F. Ahlemann, "Beyond Business-IT Alignment - Digital Business Strategies as a Paradigmatic Shift: A Review and Research Agenda," pp. 4706-4715, 2017.

[26] S. De Haes and W. Van Grembergen, Enterprise Governance of Information Technology. 2015.

[27] T. Coltman, P. Tallon, R. Sharma, and M. Queiroz, "Strategic IT alignment: Twenty-five years on," J. Inf. Technol., vol. 30, no. 2 , pp. 91-100, 2015.

[28] F. Imgrund, M. Fischer, C. Janiesch, and A. Winkelmann, "Approaching digitalization with business process management," Proc. MKWI, pp. 1725-1736, 2018

[29] A. Siurdyban, "Understanding the IT/business partnership: A business process perspective," Inf. Syst. Front., vol. 16, no. 5, pp. 909-922, 2014

[30] C. Heckmann, "The Impact of Business Process IT Ambidexterity on Business Process Performance," in ECIS 2015 Research- in-Progress Papers, 2015, pp. 0-12.

[31] A. Ferraris, F. Monge, and J. Mueller, “Ambidextrous IT capabilities and business process performance: an empirical analysis," Bus. Process Manag. J., 2018.

[32] N. G. Carr, "IT Doesn't Matter With Letters to the Editor," Educ. Rev., no. 38, pp. 24-38, 2003

[33] L. Gastaldi, F. P. Appio, M. Corso, and A. Pistorio, "Managing the exploration - exploitation paradox in healthcare," Bus. Process Manag. J., 2018.

[34] K. Hinkelmann, A. Gerber, D. Karagiannis, B. Thoenssen, A. Van Der Merwe, and R. Woitsch, "A new paradigm for the continuous alignment of business and IT: Combining enterprise architecture modelling and enterprise ontology," Comput. Ind., vol. 79, pp. 77-86, 2016

[35] M. Tarafdar and S. R. Gordon, "Understanding the influence of information systems competencies on process innovation: A resource-based view," J. Strateg. Inf. Syst., vol. 16, no. 4, pp. $353-392,2007$.
[36] H. Ling, F. Zhao, and Y. Wang, "Impact of Synergy Between IT and Business Process on Organizational Performance: a Perspective of Ambidexterity Theory," in PACIS 2009 Proceedings, 2009, vol. 116.

[37] P. E. Renaud and S. D. Bot, "Enabling Process Alignment for IT Entrepreneurship," Technol. Innov. Manag. Rev., vol. 2, no. 11, pp. 13-20, 2012.

[38] J. Ohlsson, S. Han, and H. Bouwman, "The prioritization and categorization method (PCM) process evaluation at Ericsson: a case study," Bus. Process Manag. J., vol. 23, no. 2, pp. 377-398, 2017

[39] R. W. Gregory, M. Keil, and J. Muntermann, "Paradoxes and the Nature of Ambidexterity in IT Transformation Programs," Inf. Syst. Res., pp. 1-51, 2014

[40] A. Van Looy and J. Van den Bergh, "The Effect of Organization Size and Sector on Adopting Business Process Management," Bus. Inf. Syst. Eng., 2017

[41] S. Bresciani, A. Ferraris, M. Del Giudice, and M. Del Giudice "The management of organizational ambidexterity through alliances in a new context of analysis: Internet of Things (IoT) smart city projects," Technol. Forecast. Soc. Change, p. , 2016.

[42] K. Palm and J. Lilja, "Key enabling factors for organizational ambidexterity in the publc sector," Int. J. Qual. Serv. Sci., vol. 9 , no. 1, p. 282,2016

[43] R. Matheus and M. Janssen, "Towards an ambidextrous government," in Proceedings of the 17th International Digital Government Research Conference on Digital Government Research - dg.o '16, 2016, pp. 334-341.

[44] M. L. Tushman and C. A. O'Reilly, “Ambidextrous Organizations: Managing Evolutionary and Revolutionary Change," Calif. Manage. Rev., vol. 38, no. 4, pp. 7-30, 1996

[45] J. Birkinshaw, "Building ambidexterity into an organization," MIT Sloan Manag. Rev., vol. 45, no. 4, pp. 47-55, 2004.

[46] S. De Haes and W. Van Grembergen, Business/IT Alignment Enterprise Governance of Information Technology. 2015.

[47] A. Van Looy, M. De Backer, G. Poels, and M. Snoeck, "Choosing the right business process maturity model," Inf. Manag., vol. 50, no. 7, pp. 466-488, 2013.

[48] A. Van Looy, "A Quantitative Study of the Link Between Business Process Management and Digital Innovation," in BPM Forum 2017, 2017, vol. 329, pp. 177-192.

[49] Hevner, March, Park, and Ram, "Design Science in Information Systems Research,” MIS Q., vol. 28, no. 1, p. 75, 2004.

[50] S. T. March and G. F. Smith, "Design and natural science research on information technology," 1995.

[51] S. K. Boell and D. Cecez-Kecmanovic, "On being 'systematic' in literature reviews in IS," J. Inf. Technol., vol. 30, no. 2, pp. 161$173,2015$.

[52] C. Gibson and J. Birkinshaw, "Antecedents, consequences, and mediating: Role of organizational ambidexterity," Acad. Manag. $J .$, vol. 47, no. 2, pp. 209-226, 2004

[53] C. Heckmann and A. Maedche, "IT ambidexterity for business processes: the importance of balance," Bus. Process Manag. J., vol. 24 , no. 4 , pp. $862-881,2018$.

[54] M. Röglinger, L. Schwindenhammer, and K. Stelzl, "How to Put Organizational Ambidexterity into Practice-Towards a Maturity Model," in 16th International Conference on Business Process Management, 2018. 